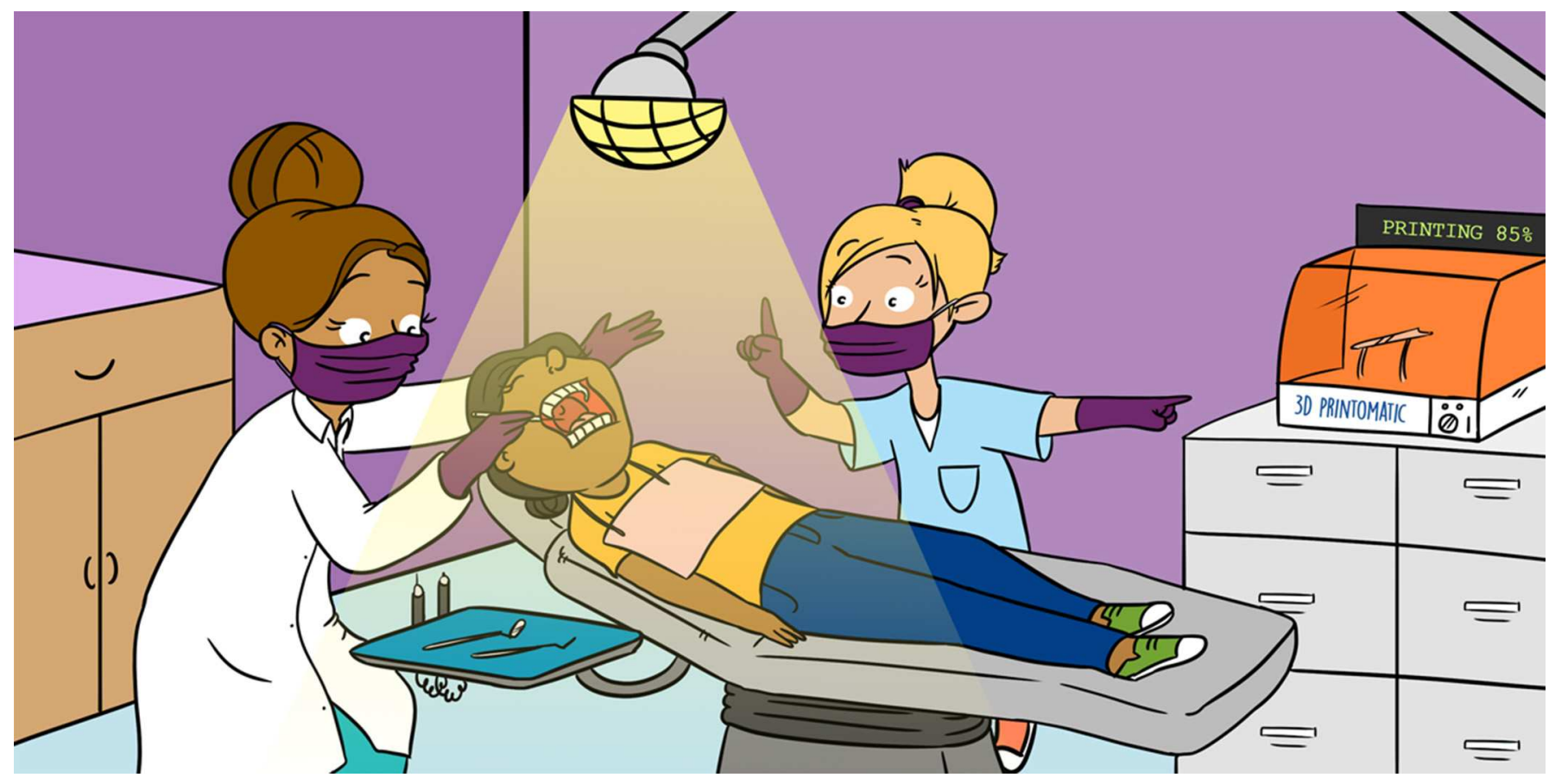

\title{
MATERIALIZING! WHAT CAN DENTISTS DO WITH 3D PRINTERS?
}

\section{Gunpreet Oberoi ${ }^{1,2,3}$, Sophie Nitsch ${ }^{1,2,4}$, Michael Edelmayer ${ }^{2,5}, K_{\text {Lara Janjic }}{ }^{1,2}$, Anna Sonja Müller ${ }^{1,2}$ and Hermann Agis ${ }^{1,2 *}$}

${ }^{1}$ Department of Conservative Dentistry and Periodontology, University Clinic of Dentistry, Medical University of Vienna, Vienna, Austria

${ }^{2}$ Austrian Cluster for Tissue Regeneration, Vienna, Austria

${ }^{3}$ Center for Medical Physics and Biomedical Engineering, Medical University of Vienna, Vienna, Austria

${ }^{4}$ Department of Health Sciences, FH Campus Wien, University of Applied Sciences, Vienna, Austria

${ }^{5}$ Department of Oral Surgery, University Clinic of Dentistry, Medical University of Vienna, Vienna, Austria

YOUNG REVIEWER:

ELIANA

AGE: 12
Imagine you can form whatever tool you need with just one click! Sounds like sci-fi. 3D printing is a novel tool that will change your experience at the dentist. Today, we can print plastics, ceramics, metals, and even live cells. Printing teeth would be the ultimate goal for dentists. To date, we have printed 3D models of patients' teeth and jaws. These models are used to plan dental treatment, show the patient the expected results, and treat certain dental issues. The results can be displayed digitally on a computer and as a 3D-printed model. This increases the patients' enthusiasm and involvement in their treatments. Also, dental students are being trained using 3D-printed models. 3D printing can be used to manufacture parts for treating bone fractures and for covering broken teeth with caps. It can also be used to create tooth-colored fillings or dental braces. 
Figure 1

Different kinds of 3D printers. There are several different kinds of 3D printing technologies available today. These include fused deposition modeling, in which hot melt material is used to deposit filaments layer by layer; selective laser sintering, in which UV light is used to cure the powder deposited in a specific pattern; stereolithography, in which UV light is used to cure the resin deposited in a specific pattern; polyjet printing, in which the printer jets drops of photopolymer that become solid by UV light; and bioprinter, in which the cells are layered between water-based layers until the tissue is built. Adopted and modified from the article Oberoi et al. [2] with permission. Further references and sources can be found in Oberoi et al. [2] .

\section{ADDITIVE \\ MANUFACTURING}

The process of joining materials to make objects from 3D model data, usually layer upon layer. It is also referred to as $3 \mathrm{D}$ printing.

\section{DIGITAL MODEL}

A 3D image of an object on a computer. 3D PRINTERS

Machines which allow to make objects from 3D model via additive manufacturing layer by layer.

\section{DENTIST}

A doctor who treats teeth.

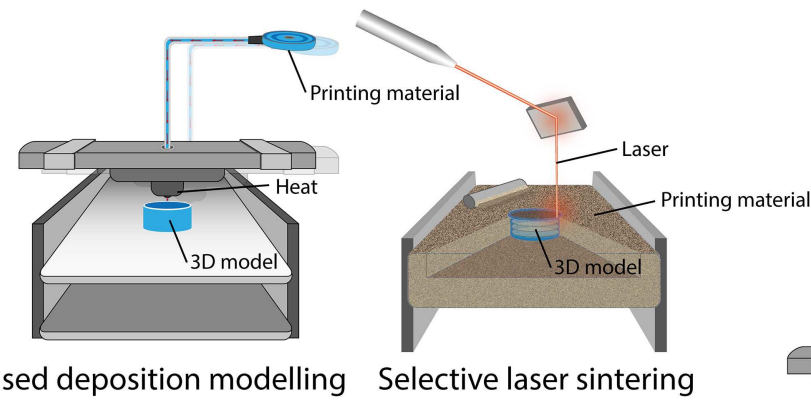

Fused deposition modelling Selective laser sintering

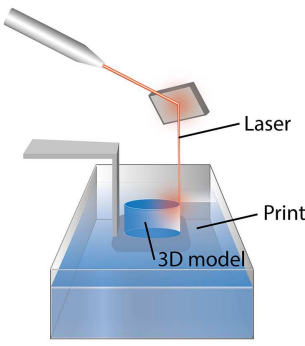

Stereolithography

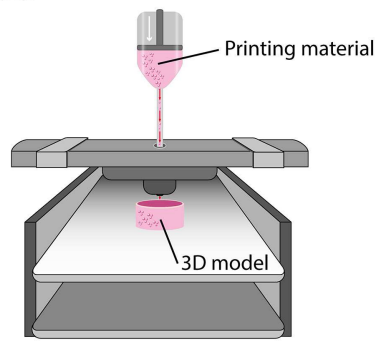

Bioprinting

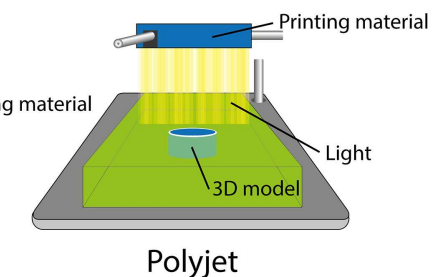

Figure 1

\section{So, 3D printing is a promising tool for advancing dental treatment and education.}

\section{WHAT IS 3D PRINTING AND HOW CAN DENTISTS USE IT?}

Have you ever seen a sci-fi movie in which the astronauts on a spaceship can materialize whatever is needed using a replicator, like in Star Trek? In these movies, the doctors can even heal wounds by materializing new tissue inside the body. This sounds like science fiction or magic, however, there is an emerging technology that brings these amazing feats closer to reality. 3D printing, also known as additive manufacturing, is defined by the Oxford dictionary as the process of making a physical object from a three-dimensional digital model by building one layer over another layer using a robotic device. A variety of materials, including plastics, metals and ceramics, in different states (powder/ liquid/ gel) can be used in 3D printers. Highly advanced 3D printers are currently being used in hospitals and universities, and small portable systems are available across the globe. Small, low-cost, portable 3D printers are becoming increasingly popular in dental clinics, too. In the past 10 years, we have seen a rapid increase in the use of 3D printing in dentistry. It allows treatment that is "patient-specific," meaning it is customized to the needs of the patient. In addition, 3D printing technology makes it very easy to share the patients' data with other dentists and technicians with just one click on the computer. This sharing helps when dentists need to discuss treatment options with their colleagues. 
Figure 2

Uses of 3D printing in dentistry. What could a dentist use a 3D printer for? In the field of oral and maxillofacial surgery, the dentist can print models of a patient's mouth, guides that help the dentist during the surgery, and artificial bone. In the field of prosthodontics, dentists can print artificial teeth and prostheses. In the field of orthodontics, dentists can print dental models and clear aligners to reposition teeth. In endodontics, dentists can produce guides for root canal treatments. In the field of periodontics, bioprinting could be a future tool for producing oral tissue for transplantation. The figure is adopted and modified from the article Oberoi et al. [2] with permission. Further references and sources can be found in Oberoi et al. [2].

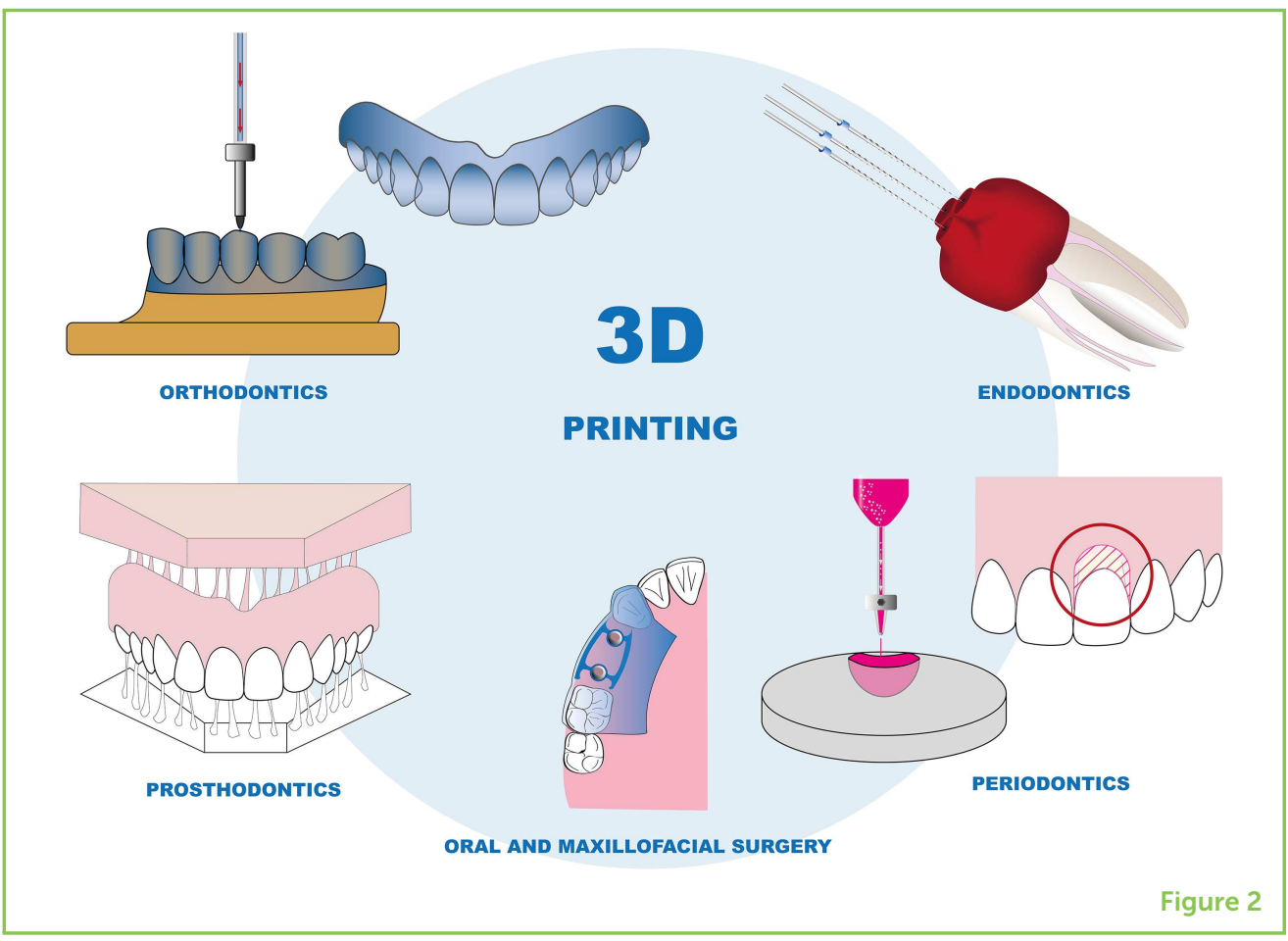

A variety of 3D printers are available, mainly differing in the source of light and the material used for 3D printing (Figure 1). There are three main steps of 3D printing. The first step is to obtain a digital 3D image of the object to be printed, using various types of 3D scanners. Then, this digital information must be converted into a form easily understood by the 3D printer, called an STL. This is done using computer software. At this stage, we can design the future object on the computer. The last step is to send this STL file to the printer so that the 3D model can be printed. Keep reading to find out about some ways that dentists have been using 3D printing to provide better oral care for their patients (Figure 2).

\section{D-PRINTED TOOLS TO HELP WITH ORAL SURGERIES}

For surgeries of the face and mouth, the dentist can use 3D imaging and scanning to get the information to make a 3D digital model of the region that will be operated on. These models make it easier to examine all the parts of the face or mouth [1]. Surgical guides and cutting drills can be created based on these 3D-printed models, which are similar to stencils. These stencils help the dentist to perform accurate operations and cause less damage to the neighboring healthy muscles and bones. Additionally, a dental surgeon can practice complicated surgical procedures, like bone cutting, tumor removal, implant placement, or fracture repair on $3 \mathrm{D}$ printed models before performing the actual surgery on the patient. 


\section{D-PRINTED TOOLS TO HELP BUILD PROSTHESES}

In order to replace missing teeth or parts of the face, skull or jawbone, a dental surgeon can make artificial parts, called prostheses (singular: prosthesis), that look similar to the original body parts. 3D printing has led to amazing advances in this field of dentistry [2]. It will soon be possible to produce highly accurate prostheses from materials like plastic, ceramics (like porcelain), metals, and flexible silicon, in the same color and shape as the patient's own face. After scanning the teeth and gums of the patient's father or mother with a small camera, 3D models of the jaw are created using 3D printing. The 3D jaw model can then be used to produce the perfect prosthesis for the missing teeth. This can reduce the time patients need to spend at the dentist. This technology is especially helpful in case of cancer patients that need to have large parts of their mouths or faces replaced after cancer therapy. These replacements help the cancer patients to look and feel beautiful, since the replacement parts are so similar to their real body parts.

\section{ALIGNERS}

Devices, which you wear in your mouth to line the teeth up properly.

\section{ROOT CANAL}

Canals within teeth in which you find the living pulp tissue.

\section{D-PRINTED TOOLS FOR REPOSITIONING TEETH}

Gone are the days of wearing embarrassing metal braces for correcting crooked teeth. With 3D printing, it is possible to print transparent "jackets" or aligners for all teeth to help line them up properly. These aligners apply force on the improperly positioned teeth to bring them in line with the other teeth [3]. Aligners not only look nicer than metal braces, they are also easier to use. They also save the roots of the teeth from damage caused by the strong forces applied by metal braces. In addition, 3D printing technology used for this purpose also provides the opportunity for dentists to store all patients' scans and information digitally and to print it whenever it is needed, saving them space and time.

\section{D-PRINTED TOOLS FOR ROOT CANAL TREATMENT}

Your parents probably tell you to brush your teeth so that you do not get cavities, which are also called dental caries. We all know that if dental caries is not treated in time, it can grow deeper into the pulp of the tooth, causing a root canal infection. When X-rays are used to examine the teeth, the dentist can only examine the roots from one direction. 3D imaging using techniques called CT scan or MRI can help the dentist to see the roots from all directions. 3D-printed root canal guides designed from these 3D scans can assist the dentist in accessing the root canals to remove the damaged pulp tissue. This greatly reduces the treatment time and provides more accurate results [4]. 


\section{BIOPRINTING}

The process of combining cells, growth factors, and biomaterials by 3D printing to build biomedical parts that are similar to natural tissue.

\section{TISSUE}

\section{ENGINEERING}

The use of a combination of cells and methods to improve, replace or form new biological tissues.

\section{D-PRINTED TOOLS TO REPAIR GUMS AND SUPPORTING TISSUE}

Healthy gums are important for oral health. Unfortunately, it is still quite common for people to have gum problems which, in some cases, need to be treated surgically. 3D-printed surgical guides can be used to help the dentist cut accurately, which is better than free-hand cutting of the gums. These guides allow the dentist to plan and design your smile before surgery. It is also possible to print a model of the results to show to the patient, so that the patient can better understand the treatment. But imagine if we could print the new tissue! Researchers all over the world are working on bringing this technology into the clinic. By printing tissues, which is commonly called "bioprinting," we will soon be able to produce 3D-printed tissues to replace missing or diseased parts of the bone and gums [5] - just like in sci-fi movies. This approach is termed tissue engineering.

\section{D PRINTING TO TRAIN DENTAL STUDENTS}

Dental students all over the world are trained on mannequins and artificial tooth/jaw models that are made from techniques other than 3D printing. These models are quite simple and do not represent the real situations seen in patients. This makes it difficult for students when they move from the models to real-life situations. 3D printing can help to provide dental students with more life-like situations for training. This kind of training will decrease the chances that new dentists will make mistakes when they actually start treating patients. As 3D printing improves, training models will become more and more realistic, duplicating the texture, hardness, softness, flexibility, and color of actual tissue. This will be an added benefit for dental students. So, you can see that 3D printing will play an increasingly important role in the training of future dentists.

\section{TAKE HOME MESSAGE}

After reading this article, it is probably clear to you that 3D printing is a growing field with several important applications in dentistry. 3D printing can improve the quality of dental treatment by making it more personalized and accurate. For dental students, 3D-printed models are the most advanced and helpful way to train, since they come close to matching the real-life situations. As research continues at a rapid pace, 3D printing helps dentists to deliver better overall oral healthcare and will help transform dentistry in to a sci-fi-like profession! Maybe one day in the future, when we fly to the stars, we will have a replicator like the one in Star Trek that can materialize new teeth whenever we need them! 


\section{AUTHOR CONTRIBUTIONS}

GO and SN were involved in study design, literature research, data analysis, and writing the manuscript. $M E, K J$, and $A M$ were involved in the study design, study, and manuscript preparation. HA was involved in study design, data analysis, writing, and submission of the manuscript.

\section{ACKNOWLEDGMENTS}

Research of the authors on 3D printing within the M3dRES project (nr. 858060) was supported by the Austrian Research Promoting Agency (FFG). Further references and sources can be found in Oberoi et al. [2].

\section{REFERENCES}

1. Alrasheed, A. S., Nguyen, L. H. P., Mongeau, L., Funnell, W. R. J., and Tewfik, M. A. 2017. Development and validation of a 3D-printed model of the ostiomeatal complex and frontal sinus for endoscopic sinus surgery training. Int. Forum Allergy Rhinol. 7:837-41. doi: 10.1002/alr.21960

2. Oberoi, G., Nitsch, S., Edelmayer, M., Janjić, K., Müller, A.S., and Agis, H. 2018. 3D printing-encompassing the facets of dentistry. Front. Bioeng. Biotechnol. 6:172. doi: 10.3389/fbioe.2018.00172

3. Martorelli, M., Gerbino, S., Giudice, M., and Ausiello, P. 2013. A comparison between customized clear and removable orthodontic appliances manufactured using RP and CNC techniques. Dent. Mater. 29:e1-10. doi: 10.1016/j.dental.2012.10.011

4. Nayak, A., Jain, P. K., Kankar, P. K., and Jain, N. 2018. Computer-aided design-based guided endodontic: a novel approach for root canal access cavity preparation. Proc. Inst. Mech. Eng. H 232:787-95. doi: 10.1177/0954411918788104

5. Li, Z., Liu, Y. S., Ye, H. Q., Liu, Y. S., Hu, W. J., and Zhou, Y. S. 2017. Diagnossis and treatment of complicated anterior teeth esthetic defects by combination of whole-process digital esthetic rehabilitation with periodontic surgery. Beijing $\mathrm{Da}$ Xue Xue Bao 49:71-5.

SUBMITTED: 13 December 2018; ACCEPTED: 13 June 2019; PUBLISHED ONLINE: 16 July 2019.

EDITED BY: Fulvio D'Acquisto, University of Roehampton, United Kingdom

CITATION: Oberoi G, Nitsch S, Edelmayer M, Janjić K, Müller AS and Agis H (2019) Materializing! What Can Dentists Do With 3D Printers? Front. Young Minds 7:88. doi: 10.3389/frym.2019.00088

CONFLICT OF INTEREST STATEMENT: The authors declare that the research was conducted in the absence of any commercial or financial relationships that could be construed as a potential conflict of interest. 


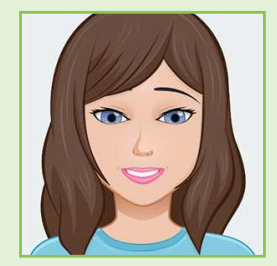

COPYRIGHT () 2019 Oberoi, Nitsch, Edelmayer, Janjić, Müller and Agis. This is an open-access article distributed under the terms of the Creative Commons Attribution License (CC BY). The use, distribution or reproduction in other forums is permitted, provided the original author(s) and the copyright owner(s) are credited and that the original publication in this journal is cited, in accordance with accepted academic practice. No use, distribution or reproduction is permitted which does not comply with these terms.

\section{YOUNG REVIEWER}

\section{ELIANA, AGE: 12}

I have many hobbies! I love reading, writing, science, history, politics, acting, running, basketball, and tennis. I am very active in my community and participate in many volunteer opportunities.

\section{AUTHORS}
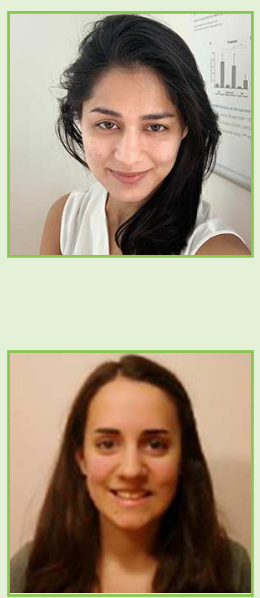

\section{GUNPREET OBEROI}

Gunpreet Oberoi is a Dental Implantologist, currently pursuing a Ph.D. and working as a Research Associate at the Medical University of Vienna. Her interdisciplinary research work is based on Tissue Engineering, Biomedical Engineering, and 3D Printing. With her versatile skills and contribution in research she aims to make standard healthcare accessible among all the social strata.

\section{SOPHIE NITSCH}

Sophie Nitsch studied Biomedical Science at the FH Campus Wien, University of Applied Sciences, Vienna, Austria where she received the Bachelor of Science in Health Studies (B.Sc.). Her thesis focused on the evaluation of novel 3D printing materials for fused deposition modeling. Currently she is pursuing the Master Program on Tissue Engineering and Regenerative Medicine at the University of Applied Sciences Technikum Wien, Vienna, Austria.

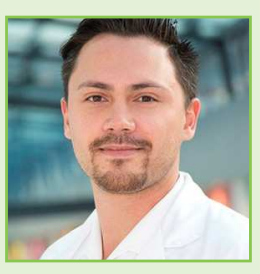

\section{MICHAEL EDELMAYER}

Michael Edelmayer is an Oral Surgeon and Head of the Special Clinic for Oral Pathology at the University Clinic of Dentistry of the Medical University of Vienna, Austria. Due to his experience he contributed to this research in the field of oral and maxillofacial surgery. He is currently conducting his Ph.D. in the field of Tissue Engineering and Bone Regeneration mentored by Hermann Agis. Starting in September 2019 he will move to Connecticut, USA, doing research, teaching students, and to clinically work at UCONN Health (University of Connecticut) for one year supported by a scholarship.

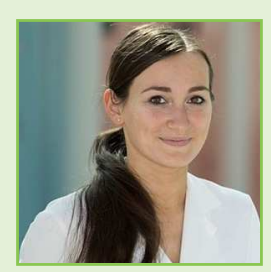

\section{KLARA JANJIC}

Klara Janjic is a Biomedical Scientist, currently working on her Ph.D. project at the University Clinic of Dentistry, Medical University of Vienna, Austria. The aim of the Ph.D. project is to study and develop different cell culture models and microtissues made from human oral cells and to find out how they can be used for basic research as well as for testing substances or materials. Besides, Klara Janjic is assisting at 

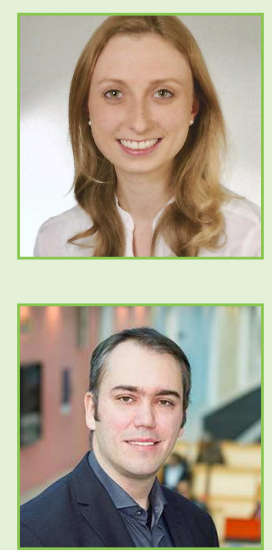

different tasks at the Center for Forensic Medicine in Vienna which is the oldest institution for Forensic Medicine in the world.

\section{ANNA SONJA MÜLLER}

Anna Sonja Müller finished her medical studies at the Medical University of Graz in 2016. She is now a Ph.D. student at the University Clinic of Dentistry, Medical University of Vienna. Her research focuses on scaffolds involved in Oral Tissue Engineering strategies as well as hypoxia-based strategies in this field.

\section{HERMANN AGIS}

Hermann Agis is a Biotechnologist by training and an Associate Professor at the University Clinic of Dentistry, Medical University of Vienna in Austria and Head of the Competence Center for Tissue Engineering and Cell-Based Therapies. Inspired by the clinical practice in Dentistry he focuses his research on Oral Tissues Regeneration. He applies molecular and cellular techniques to evaluate the mechanisms underlying regeneration and the response to biologicals, pharmaceuticals, and biomaterials. Since the beginning of his career, Hermann Agis supports young scientists in their profession. He is actively involved in mentoring programs, in the ECTS Academy and as CED-IADR Ambassador. *hermann.agis@meduniwien.ac.at. orcid.org/0000-0001-9509-1555. 